\title{
Images Are More than Documentation: They Are Research Data
}

\author{
Faten Dhawi* \\ Biotechnology Department, AlHofuf, AlAhsa King Faisal University, Saudi Arabia
}

Received: January 16, 2018; Published: January 22, 2018

*Corresponding author: Faten Dhawi, Biotechnology Department, AlHofuf, AlAhsa King Faisal University, Saudi Arabia; Email: falmuhanna@kfu.edu.sa, dr.faten.dhawi@gmail.com

\section{Opinion}

Plant leaf analysis is one of the reliable methods for estimating plant's need for fertilization [1,2], plant pigments and physiological association [3] plant shape and pigments and genetic variation [4]. Therefore, the analysis of plant leaves is complementary part of the soil analysis nutritional situation and shortfall in the economic crop prevention. In order to make the best use of plant analysis, we have to pay attention to the selection of the appropriate tissue or plant organs for analysis according to plant type and age. It is worth mentioning that concentrations of different substances in plant leaves are not constant but vary according to basic conditions and physiological age [5]. There are many methods for plant leaves analysis but recent trend is toward the non-destructive methods [68]. For instance, leaves shape, pigmentation and area measurements can be scored from photo. In this century, images are no longer just picture they are data [9]. There is several studies used software for images data analysis. There are Gimp [10], Image J [11] and Adobe Photoshop CS5 [12].

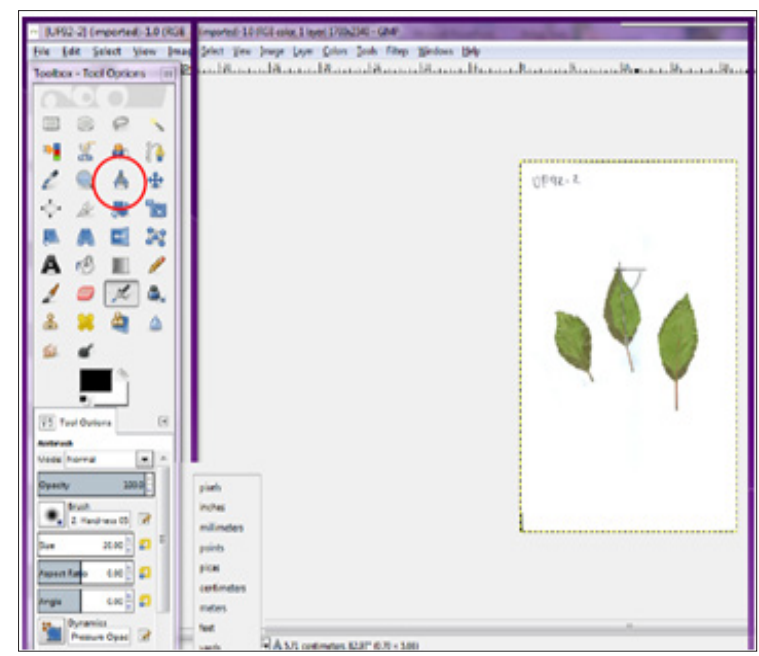

Figure 1: Leaf width and length estimated using the GIMP measure tool with centimeter.

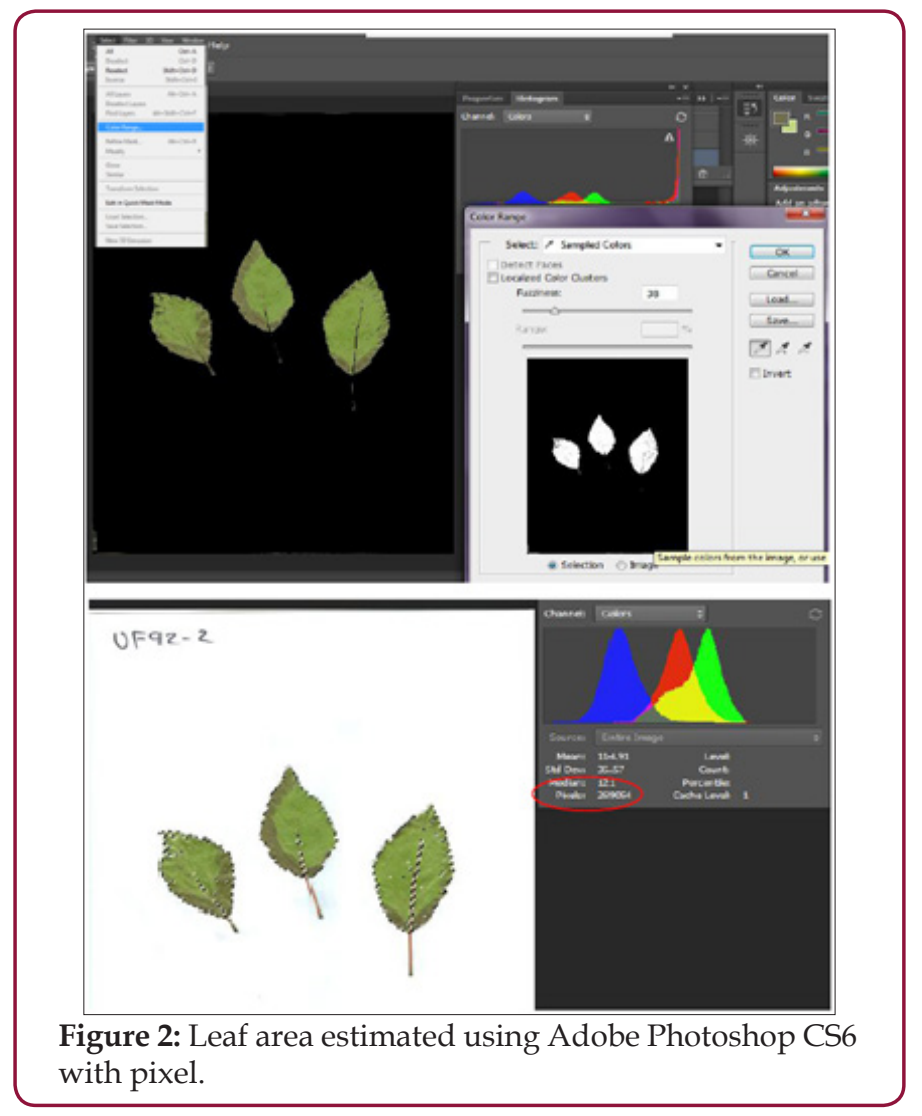

In one of our studies, to facilitate fieldwork we transferred leaves through scanned images to perform measurements from saved images. The same leaves labelled and saved at $-80^{\circ} \mathrm{C}$ for genetic analysis. We performed leaves measurements per leaf area, width, length and number of teeth. The number of teeth recorded by direct counting from images for leaf both sides. Leaves length and width recorded from scanned images using Gimp free software [13] (Figure 1). The same scanned images were used to calculate leaf area using Adobe Photoshop CS6 (Figure 2), following method 
described by Jarou et al. [14]. On the other hand [15], we used Image $\mathrm{J}$ to estimate gene expression form DNA bands image using the method described by Manohar et al. [16] (Figure 3).

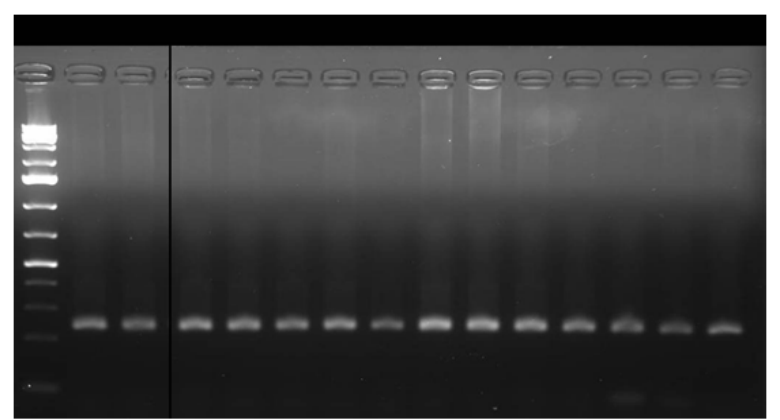

Figure 3: Gel picture processed by Image J to estimate gene expression using DNA bands image.

The use of different images processing software made it possible to correct color via automatic color correction or estimate plant area or leaf loss by scoring the preyed leaf area or studying gene expression from gel images. However, question remains what is the best tool to assess image data. Many factors might contribute for imaging tool preference. The main factor if it was free or offered at reasonable cost. The second most important factor is if it was userfriendly or accessible. The feasibility of the imaging data analysis correlated significantly with available research funds which will make the accessibility and software features is the main and the only factor affecting software use.

\section{References}

1. Khan KY, Khan MA, Niamat R, Munir M, Mazari, et al. (2011) Element content analysis of plants of genus Ficus using atomic absorption spectrometer. African journal of pharmacy and pharmacology 5(3): 317321.

2. Muñoz-Huerta RF, Guevara-Gonzalez RG, Contreras-Medina LM, TorresPacheco I, Prado-Olivarez J, et al. (2013) A review of methods for sensing the nitrogen status in plants: advantages, disadvantages and recent advances. Sensors 13(8): 10823-10843.
3. Blackburn GA (1998) Quantifying chlorophylls and caroteniods at leaf and canopy scales: An evaluation of some hyperspectral approaches. Remote sensing of environment 66(3): 273-285.

4. Tian F, Bradbury PJ, Brown PJ, Hung H, Sun Q et al. (2011) Genome-wide association study of leaf architecture in the maize nested association mapping population. Nature genetics 43(2): 159-162.

5. Kent M (2011) Vegetation description and data analysis: a practical approach. John Wiley \& Sons.

6. Gitelson AA, Merzlyak MN, Chivkunova OB (2001) Optical properties and nondestructive estimation of anthocyanin content in plant leaves. Photochemistry and photobiology 74(1): 38-45.

7. Fassnacht FE, Stenzel S, Gitelson AA (2015) Non-destructive estimation of foliar carotenoid content of tree species using merged vegetation indices. Journal of plant physiology 176: 210-217.

8. Simko I, Hayes RJ, Furbank RT (2016) Non-destructive Phenotyping of Lettuce Plants in Early Stages of Development with Optical Sensors. Frontiers in plant science 7: 1985.

9. Gillies RJ, Kinahan PE, Hricak H (2015) Radiomics: images are more than pictures, they are data. Radiology 278(2): 563-577.

10. Sparavigna A C (2015) An image processing approach based on Gnu Image Manipulation Program Gimp to the panoramic radiography. International Journal of Sciences 4(5): 57-67.

11. Scudamore CL, Soilleux EJ, Karp NA, Smith K, Poulsom R, et al. (2016) Recommendations for minimum information for publication of experimental pathology data: MINPEPA guidelines. The Journal of pathology 238(2): 359-367.

12. Wright K, Herro H (2015) Photoshop® Assisted Spectroscopy: An Economical and Non-Destructive Method for Tracking Color Shift. Topics in photographic preservation 16: 148-155.

13. Gimp free software.

14. Jarou ZJ, Weise SE, Sharkey TD (2009) Plant Growth Analysis \& TimeLapse Characterization of Starch Metabolism Mutants. Great Lakes Bioenergy Research Center Annual Retreat, South Bend, IN, USA.

15. Measuring Leaf Area with Adobe Photoshop 3.

16. Manohar M, Choi HW, Manosalva P, Austin CA, Peters JE, et al. (2017) Plant and Human MORC Proteins Have DNA-Modifying Activities Similar to Type II Topoisomerases, but Require One or More Additional Factors for Full Activity. Molecular Plant-Microbe Interactions 30(2): 87-100.

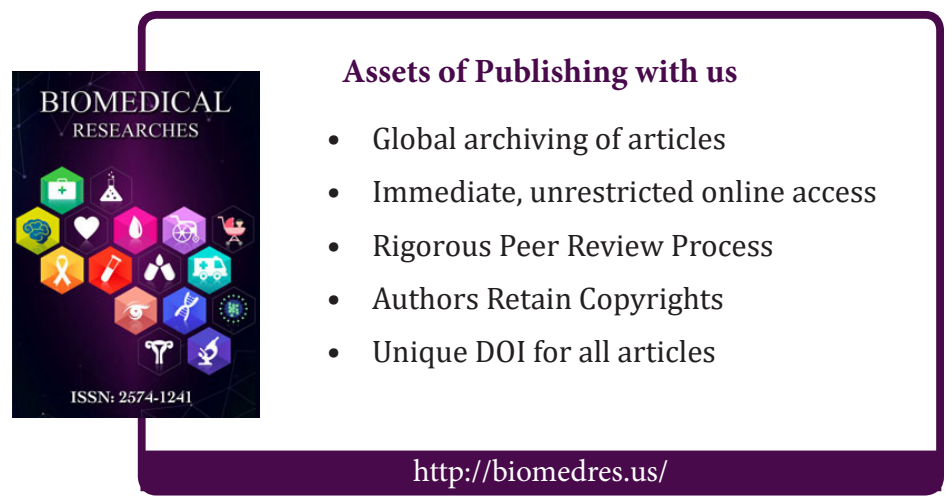

